\title{
REÇETESİZ SATILAN FARKLI BEYAZLATMA ÜRÜNLERİNİN RENKLENDİRİLMİŞ NANO VE MİKRO HİBRİT KOMPOZİTLERİN RENK DEĞİŞİMLERİ ÜZERİNE ETKİsí
}

\section{COMPARISON OF THE COLOR CHANGE EFFECTS OF OVER-THE-COUNTER WHITENING PRODUCTS ON THE DISCOLORED NANO AND MICRO HYBRID COMPOSITE RESINS}

\section{Dr. Öğr. Üyesi Burak ÇARIKÇIOĞLU*}

Makale Kodu/Article code: 4434

öz

Amaç: Bu çalışmanın amacı; renklendirici solüsyonlarda bekletilen döıt farklı kompozit rezin materyalinin, beyazlatıcı etkili ağız gargarası veya diş macunu uygulamaları ile oluşan renklenmeyi giderme üzerine hangi beyazlatma ürününün daha etkili olduğunun in vitro olarak değerlendirilmesidir.

Gereç ve Yöntem: Dört farklı kompozit rezinden (bir Nano-seramik (Zenit, President Dental), bir Nano-fil (Filtek Ultimate, 3MESPE), bir Nano-hibrit akışkan (Premise, Kerr Corporation) ve bir Mikro-hibrit (Gradia Direct Anterior, GC) $5 \mathrm{~mm}$ çapında ve $2 \mathrm{~mm}$ derinliğinde toplam 80 adet $(n=20)$ disk şeklinde örnekler hazırlandı ve başlangıç renk ölçümleri yapıldı. Her bir materyal grubunda hazırlanan örnekler rastgele gargara ve diş macunu grubu olarak iki alt gruba ayrıldı. Tüm örnekler sırasıyla, altı gün çay ve sonrasında altı gün kahve içerisinde renklenmeleri için bekletildi. Gargara alt grubundaki örnekler $(n=10) 12$ günlük renklendirme periyodu sonrasında Listerine Advanced White (Johnson\&Johnson) beyazlatıcı ağız bakım gargarasında 12 saat bekletilerek beyazlatma işlemine tabii tutuldu. Diş macunu alt grubundaki örnekler $(n=10)$ elektrikli diş firçası kullanılarak günde bir defa beyazlatıcı diş macunu İpana 3D White Luxe Perfection (Procter \& Gamble) ile 12 günlük renklendirme periyodu boyunca fırçalandı. Örneklerin renklendirme işlemi öncesi ve beyazlatma işlemleri sonrası arasındaki renk farklılıkları CIEDE2000 formülü kullanılarak hesaplandı. İstatistiksel analizler iki yönlü varyans analizi ve Bonferroni testi ile yapıldı. $(p<0,05)$

Bulgular: Gargara ve diş macunu alt grubundaki örnekler karşılaştırıldığında aralarında istatistiksel olarak fark bulunmuş $(<0.001)$, gargara alt grubundaki örneklerin renk değişim değeri $\left(\Delta \mathrm{E}_{00}\right)$, diş macunu alt grubundaki örneklere göre daha yüksek bulunmuştur. Gradia Direct haricinde diğer kompozit rezinlerin renk değişim değerleri kabul edilebilirlik eşik değerinin üzerinde olduğu tespit edilmiştir.

Sonuç: Kompozit rezinlerde diş macununun, gargaraya göre daha etkili bir beyazlatma sağladığı gözlemlenmiştir. Bu çalışma ayrıca nano kompozitlerin mikrohibrit kompozitlere göre daha düşük renk stabilitesine sahip olduğunu göstermiştir.

Anahtar Kelimeler: kompozit rezin, beyazlatıcı etki, ağız gargarası, diş macunu

\section{ABSTARCT}

Aim: The aim of this study was to determine the effect of application of whitening mouth rinse and toothpaste which whitening agents are more effective on remove discoloration of four different composite resins that stained with colored beverages in vitro.

Materials and Methods: Eighty disc-shaped specimens $(5 \mathrm{~mm}$ diameter, $2 \mathrm{~mm}$ deep) of a nano-ceramic (Zenit, President Dental), a nano-filled (Filtek Ultimate, 3M-ESPE), a nano-hybrid flowable (Premise, Kerr Corporation) and a micro-hybrid (Gradia Direct Anterior, GC) resin composites were prepared (20 from each) and initial colors were measured. Specimens of each material were divided into two as random mouth rinse and toothpaste subgroups. All specimens were immersed in tea for six days and coffee for six days respectively. After staining procedure the stained specimens of mouth rinse subgroups were immersed in Listerine Advanced White (Johnson\&Johnson, UK) whitening mouth rinse for 12 hours. The specimens in the toothpaste subgroups were brushed with İpana 3D White Luxe Perfection (Procter \& Gamble) toothpaste once a day using an electric toothbrush. The color difference before staining and after whitening procedures was evaluated by CIEDE2000 formula. The data were analyzed with two-way ANOVA and Bonferroni test $(p<0,05)$.

Results: A statistically difference was found between mouth rinse and toothpaste subgroups $(<0.001)$, the color change value $\left(\Delta \mathrm{E}_{00}\right)$ in mouth rinse subgroup was found higher than in toothpaste subgroup. $\Delta \mathrm{E}_{00}$ values obtained from all samples were higher than the acceptability threshold value expect Gradia Direct.

Conclusion: Toothpaste is more effective than mouth rinse on remove discoloration of composite resins. The results of this study also showed that nano composites had lower color stability than microhybrid composites.

Keywords: composite resın, color change effects, mouth rinse, toothpaste

* Canakkale Onsekiz Mart Üniversitesi, Diș Hekimliği Fakültesi, Pedodonti Anabilim Dalı, Canakkale.

Kaynakça Bilgisi: Çarıkçıŏlu B. Reçetesiz satılan farklı beyazlatma ürünlerinin renklendirilmiş nano ve mikro hibrit kompozitlerin renk değişimleri üzerine etkisi . Atatürk Üniv Diş Hek Fak Derg 2021; 31: 27-33.

Citation Information: Carıkcloglu B. Comparison of the color change effects of over-the-counter whitening products on the discolored nano and micro hybrid composite resins. J Dent Fac Atatürk Uni 2021; 31: 27-33. 


\section{GİRİŞ}

Diş hekimliğinde kompozit rezinler, artan estetik beklentileri karşılaması ve minimal invaziv yöntemlerle uygulanabilmesi nedeniyle yaygın olarak kullanılmaktadır. ${ }^{1}$ Partikül boyutları azaltılıp doldurucu miktarı arttırılarak fiziksel özelliklerinin geliştirilmesine rağmen kompozit rezinlerin renk stabilitelerini uzun süre koruyamaması, restorasyonun yenilenmesinin en önemli nedenlerindendir.2,3 Kompozit rezinlerin renk stabilitesini iç ve dış kaynaklı birçok faktör etkilemektedir. İç kaynaklı renklenmeler materyalin rezin matriks bileşimi ve doldurucu içeriği ile ilişkili iken; dış kaynaklı renklenmeler hatalı bitirme ve polisaj işlemi, kötü ağız hijyeni ve renklendirici maddelerin restorasyon yüzeyinde birikmesi sonucu meydana gelir.4,5

Rezin matriksin hidrofilitesi ve su emilim derecesi, kompozitlerin renklenmeye olan yatkınlığı ile yakından ilişkilidir. Su emilimi yüksek olan bir kompozit rezin, suda çözünen boyayıcı pigmentleri absorbe ederek renklenmeye neden olur.6,7 Kompozit rezinlerin yapısında bulunan farklı tipte ve boyuttaki doldurucu partiküllerde renk stabilitesinde önemli rol oynamaktadır. $^{8}$ 0.1-100 nm boyutlarında doldurucu içeren nanokompozitlerin renk stabilitesinin, mikrofil ve hibrit kompozitlere göre daha iyi olduğu yapılan çalışmalarda belirtilmektedir. ${ }^{9}$

Renklenmiş kompozitlerin estetik olarak kabul edilebilir hale gelebilmesi için farklı yöntemler uygulanmaktadır. Renklenmenin giderilmesi için diş fırçalama gibi mekanik yöntemlerin yanında farklı kimyasal içerikli beyazlatma ajanları da uygulanabilmektedir. ${ }^{1,10}$ Ofis tipi beyazlatma ürünleri genellikle hekim tarafından uygulanan pahalı işlemlerdir. Bunların yanında kişinin rahatlıkla ulaşıp kullanabileceği, düşük maliyetli ve beyazlatma etkisi bulunan diş macunları, ağız gargaraları, sakızlar, jeller ve beyazlatıc bantlar piyasada bulunmaktadır. ${ }^{11}$ Beyazlatma ürünleri dişlerle beraber ağızda bulunan mevcut restorasyonlarında renklerine etki edebilirler. ${ }^{12}$ Kompozit rezinlerin yapısında organik matriks bulunması, beyazlatma ajanlarından diğer restoratif materyallere göre daha fazla etkilenmesine neden olmaktadır.13 Farklı beyazlatma ürünlerinin kompozit rezinlere etkisi üzerine yapılmış çok sayıda çalışma olmasına rağmen literatürde reçetesiz satılan beyazlatıcı etkili ağız gargarası ve diş macununun renklenmiş farklı tiplerdeki kompozitler üzerine uzun dönem etkisinin karşılaştırıldığı bir çalışmaya rastlanmamıştır.
$\mathrm{Bu}$ çalışmanın amacl; farklı solüsyonlarda renklendirilmiş dört farklı kompozit rezin materyalinin beyazlatıcı etkili ağız gargarası veya diş macunu uygulamalarından oluşan renklenmeyi giderme üzerine hangi beyazlatma ürününün daha etkili olacağını in vitro olarak değerlendirmektir. Çalışma öncesi hipotezler a) gargaranın diş macununa göre renklenmiş kompozit rezinlerde daha fazla beyazlatıcı etki göstereceği ve b) nano kompozit rezinlerde, mikrohibrit kompozit rezine göre renklendirme sonrasında beyazlatıcı ürünlerin daha etkili beyazlatma sağlayacağıdır.

\section{GEREÇ VE YÖNTEM}

Bu çalışmada kullanılan 4 farklı kompozit rezin; Zenit (President Dental), Filtek Ultimate (3M-ESPE), Premise (Kerr), Gradia Direct Anterior (GC), bir beyazlatıcı ağız gargarası; Listerine Advanced White (Johnson\&Johnson) ve bir beyazlatıcı diş macunu; İpana 3D White Luxe Perfection (Procter \& Gamble) içerikleri Tablo 1'de verildi.

Tablo 1. Çalışmada kullanılan materyallerin adı, üretici firmaları, tipi ve kompozisyonları.

\begin{tabular}{|c|c|c|c|}
\hline Ürün adı & $\begin{array}{l}\text { Üretici } \\
\text { Firma }\end{array}$ & Tipi & Kompozisyon \\
\hline Zenit & $\begin{array}{l}\text { President } \\
\text { Dental, } \\
\text { Münih, } \\
\text { Almanya }\end{array}$ & $\begin{array}{l}\text { Nano- } \\
\text { seramik } \\
\text { kompozit } \\
\text { rezin }\end{array}$ & $\begin{array}{c}\text { Ağırlıkça \%83 doldurucu; cam dolgu (0.7 } \\
\mu \mathrm{m}) \text {, pirojenik silika }(12 \mathrm{~nm}) \text {, agglomere } \\
\text { nano partiküller }(0.6 \mu \mathrm{m}), \\
\text { diüretanmetakrilat, butanediol } \\
\text { dimetakrilat, Bis-GMA }\end{array}$ \\
\hline $\begin{array}{c}\text { Filtek } \\
\text { Ultimate }\end{array}$ & $\begin{array}{l}\text { 3M ESPE, } \\
\text { St. Paul, } \\
\text { ABD }\end{array}$ & $\begin{array}{l}\text { Nano-fil } \\
\text { kompozit } \\
\text { rezin }\end{array}$ & $\begin{array}{c}\text { Ağırlıkça \%78,5 doldurucu; Silika }(20 \mathrm{~nm}) \text {, } \\
\text { Zirkonya }(4-11 \mathrm{~nm}), \text { Bis-GMA, UDMA, } \\
\text { TEGDMA, PEGDMA, Bis-EMA }\end{array}$ \\
\hline Premise & $\begin{array}{l}\text { Kerr Hawe, } \\
\text { Kaliforniya, } \\
\text { ABD }\end{array}$ & $\begin{array}{l}\text { Nano-hibrit } \\
\text { akışkan } \\
\text { kompozit } \\
\text { rezin }\end{array}$ & $\begin{array}{c}\text { Ağırlıkça } \% 72,5 \text { doldurucu; Pre-polimerize } \\
\text { rezin }(30-50 \mu \mathrm{m}), \text { baryum camı }(0.4 \mu \mathrm{m}), \\
\text { silika }(20 \mathrm{~nm}), \text { Etoksilenmiş bisfenol A } \\
\text { dimetakrilat, trietilen glikol dimetakrilat, } \\
\text { kamforokinon }\end{array}$ \\
\hline $\begin{array}{l}\text { Gradia } \\
\text { Direct }\end{array}$ & $\begin{array}{l}\text { GC, Tokyo, } \\
\text { Japonya }\end{array}$ & $\begin{array}{l}\text { Mikro-hibrit } \\
\text { kompozit } \\
\text { rezin }\end{array}$ & $\begin{array}{c}\text { Ağırlıkça \%73 doldurucu; fluoro alumino } \\
\text { silikat cam }(0.85 \mu \mathrm{m}), \text { pre-polimerize } \\
\text { doldurucu ve silika }(0.85 \mu \mathrm{m}), \\
\text { Dimethakrilat kamforokinon, UDMA } \\
\end{array}$ \\
\hline $\begin{array}{l}\text { Listerine } \\
\text { Advanced } \\
\text { White }\end{array}$ & $\begin{array}{l}\text { Johnson\& } \\
\text { Johnson, } \\
\text { Pomezia, } \\
\text { İtalya }\end{array}$ & $\begin{array}{l}\text { Ağız } \\
\text { gargarası }\end{array}$ & $\begin{array}{c}\text { Su, Alkol, Sorbitol, Tetrapotasyum } \\
\text { Profosfat, } \\
\text { Pentasodyum Trifosfat, Sitrik asit, } \\
\text { poloxamer 407, Sodyum Benzoat, } \\
\text { Eucalyptol, Timol, Mentol, sodyum } \\
\text { sakkarin, Sodyum florid, Tetrasodyum } \\
\text { Pyrofosfat, Propilen glikol, Sucralose, } \\
\text { Aroma, Disodyum fosfat, Sodyum florür. }\end{array}$ \\
\hline $\begin{array}{c}\text { İpana 3D } \\
\text { White Luxe } \\
\text { Perfection }\end{array}$ & $\begin{array}{l}\text { Procter \& } \\
\text { Gamble, } \\
\text { Gross- } \\
\text { Gerau, } \\
\text { Almanya }\end{array}$ & Diş macunu & $\begin{array}{c}\text { Gliserin, hidrate silika, sodyum } \\
\text { hekzametafosfat, su, PEG-6, aroma, silika, } \\
\text { sodyum larül sülfat, cocamidopropil } \\
\text { betain, trisodyum fosfat, mika, chondrus } \\
\text { crispus tozu, sodyum sakkarin, PEG-20M, } \\
\text { sodyum florür, ksantan, sodyum klorit, CI } \\
77891 \text {, sukraloz, sodyum benzoat. }\end{array}$ \\
\hline
\end{tabular}

Bis-GMA: Bisfenol A Glisidil Metakrilat; PEGDMA: Polietilen Glikol Dimetakrilat; TEGDMA: Trietilen Glikol Dimetakrilat; UDMA: Üretan Dimetakrilat; Bis-EMA: Bis-Etilen Glikol Dimetakrilat.

Örnekler, üzerine şeffaf bant konularak ve her iki tarafı mikroskop camı ile kapatılan teflon kalıplar (2 $\mathrm{mm}$ kalınlığında ve $5 \mathrm{~mm}$ çapında) içerisinde hazır- 
landı. Kompozit rezinler üretici firmaların önerileri doğrultusunda LED ışık cihazı ile (Elipar Freelight II, 3M ESPE, St. Paul MN, ABD) 20 saniye boyunca polimerize edildi. Polimerizasyon cihazının ışık yoğunluğu radiometre (Hilux Ultra Plus Curing Units, Benlioğlu Dental) ile kontrol edildi. Hazırlanan tüm örnekler polimerizasyonun tamamlanması amacıyla $37^{\circ} \mathrm{C}$ distile suda 24 saat süre ile bekletildi. Ardından örnekler sırasıyla grenleri kalından inceye doğru değişen polisaj diskleri (Sof-Lex, 3M ESPE) ile su soğutması altında cilalandı. Her bir kompozit rezin grubundan 20 adet olmak üzere toplam 80 adet örnek elde edildi. Çalışmanın akış şeması Şekil 1'de verildi.

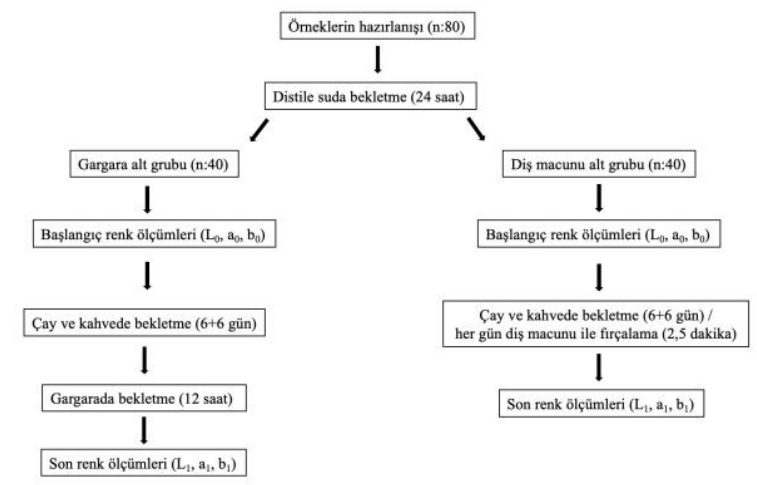

Şekil 1. Çalışmanın akış şeması.

Örneklerin renk ölçümleri için kullanılan spektrofotometre (VitaEasyshade V, Vita Zahnfabrik, Bad Sackingen, Almanya) her ölçümünden önce kendi özel kalibrasyon aleti ile kalibre edildi. Tüm örneklerin renk ölçümleri standart günışığı (CIE standard illuminant D65) aydınlatma koşullarında standart bir beyaz zemin üzerinde yapıldı. Örnekler kurutma kağıdıyla kurutulduktan sonra tam ortasından üç ardışık ölçüm yapılarak, ortalama L, a, b değerleri kaydedildi. Başlangıç renk ölçüm değerleri $37^{\circ} \mathrm{C}$ de 24 saat distile suda bekletilen örneklerden ( $\left.L_{0}, a_{0}, b_{0}\right)$ elde edildi (T0).

Ölçüm sonrasında her gruptaki örnekler rastgele gargara ve diş macunu grubu olarak iki alt gruba ayrıldı. Tüm örnekler sırasıyla, 6 gün çay (Lipton Yellow Label, Unilever, İstanbul, Türkiye; 1 adet poşet çay $250 \mathrm{ml}$ kaynamış suda 5 dak bekletilerek hazırlanmıştır) ve sonrasında 6 gün kahve (Nescafe Classic, Nestle, Bursa, Türkiye; 2 gr kahve 200 ml kaynamış suda karıştırılarak hazırlanmıştır) içerisinde renklenmeleri için bekletildi. Renklendirici solüsyonlar 12 günlük test periyodu süresince her gün yenilendi.

Gargara alt grubundaki örnekler $(n=10) 12$ gün- lük renklendirme periyodu sonrasında beş dakika boyunca distile su ile yıkandı ve kurutma kağıdı ile kurutuldu. Daha sonra örnekler Listerine Advanced White (Johnson\&Johnson, İngiltere) beyazlatıcı etkili ağız gargarasında 12 saat bekletilerek beyazlatma işlemine tabii tutuldu.

Diş macunu alt grubundaki örnekler $(n=10)$ elektrikli diş fırçası Oral-B Genius 8000 (Braun $\mathrm{GmbH}$, Kronberg, Almanya) kullanılarak günde bir kez 2,5 dakika süreyle beyazlatıcı etkili diş macunu İpana 3D White Luxe Perfection (Procter \& Gamble Gross-Gerau, Almanya) ile 12 günlük renklendirme periyodu boyunca fırçalandı. ${ }^{14}$ Diş macunu ile distile su karışımı 1:2 oranında kullanıldı. Her fırçalama işlemi sonrasında örnekler bir dakika musluk suyu altında yıkandı ve bir sonraki fırçalamaya kadar renklendirici solüsyon içerisinde bekletildi.

12. gün sonunda ( $\mathrm{T} 1)$ renklendirilmiş ve beyazlatma işlemleri tamamlanmış örneklerin ikinci renk ölçümleri daha önce tarif edildiği şekilde tekrarlandı $\left(L_{1}, a_{1}, b_{1}\right)$ ve renk değişim değerleri $\left(\Delta E_{00}\right)$ başlangıç renk ölçümleri temel alınarak aşağıdaki CIEDE2000 formülü ile hesaplandı.

$$
\Delta E_{00}=\left[\left(\frac{\Delta L^{\prime}}{K_{\mathrm{L}} S_{\mathrm{L}}}\right)^{2}+\left(\frac{\Delta C^{\prime}}{K_{\mathrm{C}} S_{\mathrm{C}}}\right)^{2}+\left(\frac{\Delta H^{\prime}}{K_{\mathrm{H}} S_{\mathrm{H}}}\right)^{2}+\mathrm{R}_{\mathrm{T}}\left(\frac{\Delta C^{\prime}}{K_{\mathrm{C}} S_{\mathrm{C}}}\right)\left(\frac{\Delta H^{\prime}}{K_{\mathrm{H}} S_{\mathrm{H}}}\right)\right]^{\frac{1}{2}}
$$

$\Delta \mathrm{E}_{00}$ değeri algılanabilirlik için 0.8 ; kabul edilebilirlik için 1.8 eşik değerleri referans alındı. ${ }^{15}$

Çalışmanın istatistiksel analizleri SPSS 21.0 (SPSS Inc. Chicago, IL, ABD) programı kullanılarak gerçekleştirildi. Verilerin normal dağılıma uygunluğunun Shapiro-Wilk testi ile kontrolü ardından iki yönlü varyans analizi ve ikili karşılaştırmalar için Bonferroni testi kullanılarak istatistiksel analiz tamamlandı. İstatistiksel olarak anlamlılık düzeyi $\mathrm{p}<0,05$ olarak kabul edildi.

\section{BULGULAR}

Çalışmada kullanılan her bir kompozit rezin ve uygulanan beyazlatma ürünü için renk değişim ortalama $\left(\Delta \mathrm{E}_{00}\right)$ ve standart sapma (SS) değerleri Tablo 2'de verilmiştir.

Yapılan iki yönlü varyans analizi, renk değişim değerleri üzerinde kompozit rezinlerin $(<0,001)$ ve beyazlatma ürünlerinin $(<0,001)$ önemli bir etkisi olduğunu ancak bunların etkileşiminin $(0,410)$ anlamlı olmadığını göstermiştir.

Tablo 2. Renk değişim ortalama $\left(\Delta \mathrm{E}_{00}\right) \pm$ standart sapma (SS) değerleri 


\begin{tabular}{|l|l|l|l|} 
Zenit & $10.32 \pm 0.66$ & $9.24 \pm 1.05$ & $9.78 \pm 1.02^{\mathrm{a}}$ \\
\hline Filtek Ultimate & $10.97 \pm 1.40$ & $9.72 \pm 0.69$ & $10.34 \pm 1.25^{\mathrm{a}}$ \\
\hline Premise & $8.62 \pm 0.47$ & $7.90 \pm 0.71$ & $8.26 \pm 0.69^{\mathbf{b}}$ \\
\hline Gradia Direct & $2.02 \pm 0.58$ & $1.58 \pm 0.59$ & $1.80 \pm 0.61^{\mathbf{c}}$ \\
\hline Ortalama & $7.98 \pm 3.69$ & $7.11 \pm 3.39$ & \\
\hline
\end{tabular}

Farklı küçük harfler, aynı sütun içerisinde istatistiksel olarak anlamlı farklılıkları ifade etmektedir $(p<0,05)$.

Gargara ve diş macunu alt grubundaki örnekler karşılaştırıldığında aralarında istatistiksel olarak fark bulunmuş (<0.001), gargara alt grubundaki örneklerin renk değişim değeri, diş macunu alt grubundaki örneklere göre daha yüksek bulunmuştur. Kompozit rezinlerin renk değişim ortalamaları arasında anlamlı farklılık vardır. Kullanılan beyazlatma ürünleri fark etmeksizin, Filtek Ultimate $(10.34 \pm 1.25)$ ve Zenit (9.78 \pm 1.02) kompozit rezinlerinin renk değişim değerleri, diğer kompozit rezin gruplarına göre anlamlı derecede yüksek bulunurken, kendi aralarında anlamlı bir farkIılık oluşturmamıştır $(p=0,351)$. Filtek Ultimate, gargara ve diş macunu alt grubunda en fazla renk değişimi gösteren kompozit rezin olmuştur. Gradia Direct'in

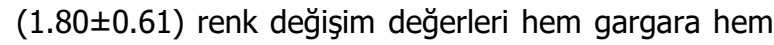
de diş macunu alt grubunda diğer kompozit rezinlere göre anlamlı derecede düşük bulunmuştur $(<0.001)$. Gradia Direct'in diş macunu alt grubunda renk değişim değeri (1.58 \pm 0.59$)$ haricinde elde edilen tüm renk değişim değerleri algılanabilirlik ve kabul edilebilirlik eşik değerinin üzerinde bulunmuştur (Tablo 2).

Çalışmada kullanılan her bir kompozit rezin ve uygulanan beyazlatma ürünü için farklı zamanlardaki " $L, a, b^{\prime}$ değerlerinin ortalama ve standart sapma (SS) değerleri Tablo 3 ve Tablo 4'te verilmiştir. T0-T1 zaman periyodları arasında, gargara alt grubunda Gradia Direct'in $b$ değeri haricinde tüm örneklerde $L, a$ ve $b$ değerleri azalma göstermiştir. Diş macunu alt grubunda ise $L, a$ ve $b$ değerleri yalnızca Gradia Direct'te artış gösterirken diğer tüm örneklerde azalma göstermiştir.

\section{TARTIŞMA}

Bu çalışmada, gelişmiş estetik ve mekanik özelliklere sahip üç farklı nano kompozit ile bir mikrohibrit kompozit rezinlerin çay ve kahve solüsyonlarında renklendirilmeleri sonrasında gargara veya diş macununun beyazlatıcı etkileri in vitro olarak karşılaştırıldı. Elde edilen sonuçlara göre, nano kompozit rezinlerde mikro hibrit kompozit rezinlere göre renklendirme sonrasında beyazlatıcı ürünlerin daha etkili beyazlatma sağladığı ve gargaranın diş macununa göre renklenmiş kompozit rezinlerde daha fazla beyazlatıcı etki gösterdiği; sıfır hipotezleri reddedilmiştir.

Tablo 3. Gargara alt grubundaki kompozit rezinlerin renk koordinatlarının ( $\left.L^{*}, a^{*}, b^{*}\right)$ ortalama \pm standart sapma (SS) değerleri ( $\mathrm{T} 0-37^{\circ} \mathrm{C}^{\prime}$ de 24 saat distile suda bekletildikten sonra; T1-12 gün renklendirme ardından 12 saat gargarada bekletildikten sonra)

\begin{tabular}{|l|l|l|l|l|}
\hline $\begin{array}{l}\text { Kompozit } \\
\text { rezinler }\end{array}$ & $\begin{array}{l}\text { Zaman } \\
\text { periyodu }\end{array}$ & $\mathbf{L}$ & $\mathbf{a}$ & b \\
\hline \multirow{2}{*}{ Zenit } & T0 & $89.61 \pm 0.5$ & $4.15 \pm 0.05$ & $22.55 \pm 0.91$ \\
\cline { 2 - 5 } & T1 & $74.83 \pm 0.62$ & $1.85 \pm 0.13$ & $20.49 \pm 0.78$ \\
\hline \multirow{2}{*}{$\begin{array}{l}\text { Filtek } \\
\text { Ultimate }\end{array}$} & T0 & $86.3 \pm 1.4$ & $1.82 \pm 0.18$ & $28.2 \pm 0.94$ \\
\cline { 2 - 5 } & T1 & $71.01 \pm 2.62$ & $1.68 \pm 0.36$ & $24.15 \pm 1.48$ \\
\hline \multirow{3}{*}{ Premise } & T0 & $88.91 \pm 1.05$ & $4.02 \pm 0.23$ & $27.03 \pm 1.55$ \\
\cline { 2 - 5 } $\begin{array}{l}\text { Gradia } \\
\text { Direct }\end{array}$ & T0 & $77.29 \pm 1.43$ & $2.08 \pm 0.33$ & $19.98 \pm 0.88$ \\
\cline { 2 - 5 } & T1 & $77.32 \pm 1.45$ & $1.88 \pm 0.42$ & $19.7 \pm 0.22$ \\
\hline
\end{tabular}

Tablo 4. Diş macunu alt grubundaki kompozit rezinlerin renk koordinatlarının ( $\left.L^{*}, a^{*}, b^{*}\right)$ ortalama \pm standart sapma (SS) değerleri $\left(\mathrm{TO}-37^{\circ} \mathrm{C}^{\prime}\right.$ de 24 saat distile suda bekletildikten sonra; T1-12 gün renklendirme ile her gün diş macunu ile fırçaladıktan sonra)

\begin{tabular}{|l|l|l|l|l|}
\hline $\begin{array}{l}\text { Kompozit } \\
\text { rezinler }\end{array}$ & $\begin{array}{l}\text { Zaman } \\
\text { periyodu }\end{array}$ & L & a & b \\
\hline \multirow{2}{*}{ Zenit } & T0 & $88.05 \pm 2.67$ & $4.17 \pm 0.05$ & $22.43 \pm 1.01$ \\
\cline { 2 - 5 } & T1 & $75 \pm 1.22$ & $1.83 \pm 0.13$ & $20.13 \pm 0.81$ \\
\hline \multirow{2}{*}{$\begin{array}{l}\text { Filtek } \\
\text { Ultimate }\end{array}$} & T0 & $87.42 \pm 1.49$ & $1.8 \pm 0.07$ & $27.74 \pm 1$ \\
\cline { 2 - 5 } Premise & T0 & $73.98 \pm 1.69$ & $0.91 \pm 0.26$ & $21.6 \pm 0.38$ \\
\cline { 2 - 5 } & T1 & $86.05 \pm 1.34$ & $3.44 \pm 0.12$ & $28.62 \pm 0.77$ \\
\hline \multirow{2}{*}{$\begin{array}{l}\text { Gradia } \\
\text { Direct }\end{array}$} & T0 & $76.21 \pm 0.74$ & $2.16 \pm 0.1$ & $20.06 \pm 0.72$ \\
\cline { 2 - 5 } & T1 & $76.77 \pm 0.98$ & $1.7 \pm 0.15$ & $19.76 \pm 0.98$ \\
\hline
\end{tabular}

Dişlerde çürük veya travma nedeniyle oluşan madde kayıplarını telafi etmek, aynı zamanda estetik ve fonksiyonel olarak uygun bir restorasyon yapabilmek için günümüze kadar birçok restoratif materyal üretilmiştir. ${ }^{16}$ Diş rengindeki kompozit rezinlerin klinik olarak uzun ömürlü olmabilmeleri renk stabilitelerini uzun süre koruyabilmelerine bağlıdır. ${ }^{2}$ Ertaş ve ark. ${ }^{17}$ mikrohibrit kompozitlerin nanohibrit kompozitlere göre daha düşük renk stabilitesine sahip olduklarını bildirmişlerdir. Yapılan başka çalışmalarda ise partikül boyutu daha küçük olan kompozit rezinlerin her zaman daha az renk değişimi göstermediği, kompozit rezinlerin doldurucu oranı ve organik matriks içeriğinin de renk stabilitesini etkilediğini belirtmişlerdir.2,18

$\mathrm{Bu}$ çalışmada kullanılan mikrohibrit kompozit rezin, nano kompozit rezinlere göre anlamlı derecede yüksek bir renk stabilitesi göstermiştir. Zenit ve Filtek Ultimate diğer kompozit rezinlere oranla ağırlıkça daha çok doldurucu içermesine rağmen renk stabilitesi diğer kompozit rezinlere göre daha düşük bulunmuştur. Bu durum çalışmamızdaki kompozit rezinlerin renk stabilitelerinin partikül boyutu ve doldurucu ağırlığından çok monomer içeriğinden etkilediğini düşündürmektedir.

Bis-GMA içeren kompozit rezinler TEGDMA içerenlere göre daha az, UDMA ve Bis-EMA içeren kompozit rezinlere göre daha fazla su emilimi gösterdiğinden renklenmeye daha yatkındır. ${ }^{19}$ Çalışmamızda UDMA içerip Bis-GMA ve TEGDMA içermeyen Gradia 
Direct'in; Bis-GMA ve TEGDMA içeren Filtek Ultimate'e ve Bis-GMA içeren Zenit ve Premise'e göre daha iyi renk stabilitesine sahip olduğu belirlenmiştir.

Kompozit rezinleri yüksek oranda renklendirdiği ${ }^{17}$ ve günlük hayatta sıklıkla tüketildiği bilinen çay ve kahve çalışmamızda renklendirici solüsyon olarak tercih edilmiştir. Renklendirici solüsyonlarda bekletilen süre Güler ve ark. ${ }^{20}$ çalışmalarındaki bir kahvenin ortalama tüketim süresini 15 dakika ve ortalama tüketimi günde 3,2 fincan referans alınarak oluşturulmuştur. Buna göre örneklerin renklendirici solüsyonlarda 12 günlük bekletilme süreleri ortalama 1 yıl boyunca tüketilen içeceği simüle etmektedir. Renklendirici solüsyonların tüketim sıklığının yanında içeriğide kompozit rezinlerin renk stabilitesine etki etmektedir. Kahvedeki düşük polar özellikteki sarı renklendirici pigmentlerin kompozit rezin tarafından emilip organik matrikse penetre olması ile renklenme meydana gelmektedir. Çaydaki sarı renklendirici pigmentler ise polaritelerinin kahveye göre daha yüksek olması nedeniyle sadece yüzeysel olarak renklenme oluşturabilmekte ve fırçalama ile uzaklaşabilmektedir. ${ }^{21}$

Diş macunları ile yapılan fırçalama işlemleri ile yüzeyde oluşan renklenmeler azaltılabilir. ${ }^{1}$ Diş macunlarının beyazlatma etkisi içeriğindeki silikanın aşındırıcı ve sodyum heksametafosfatın kimyasal etkisi sayesinde gerçekleşmektedir. ${ }^{22}$ Bezgin ve ark. ${ }^{14}$ farklı solüsyonlarda renklendirilmiş estetik restoratif materyallerde diş fırçalamanın renk değişimi üzerine etkisini değerlendirmek amacıyla restoratif materyalleri günde bir defa 5 sn boyunca elektrikli diş fırçasıyla fırçalamaya tabi tutmuşlardır. Bizim çalışmamızda bu çalışma referans alınarak bir yıllık fırçalama süresini simüle etmek için fırçalama alt grubundaki örnekler beyazlatıcı bir diş macunu ile 12 gün boyunca günde 2,5 dakika fırçalanmıştır. Fırçalama işlemi aynı uygulayıcı (B.Ç.) tarafından standart bir kuvvet altında yapılmış ve çalışmada beyazlatıcı etkili olarak piyasada bulunan İpana 3D White Luxe Perfection (Procter \& Gamble) diş macunu tercih edilmiştir.

Kompozit rezinlerde doldurucu içeriğinin boyutu büyüdükçe yüzey pürüzlülüğünün artmasına ve cilalanabilirlik özelliğinin azalmasına neden olduğu belirtilmiştir. ${ }^{23}$ Kahve ile renklendirilen prefabrik ve direkt kompozit rezinlerin fırçalama sonrası renk değişimlerinin incelendiği bir çalışmada renklenmelerin macunla fırçalama işlemi ile büyük oranda ortadan kalkabildiği, cilalanabilirlik özelliği daha iyi olan kompozitlerin daha az renk değişimi gösterdiği ve kullanılan diş macunun içeriğine göre beyazlatıcı etkisinin değiştiği belirtilmiştir. ${ }^{24}$ Çalışmamızdaki kompozit rezinler doldurucu içeriklerine göre değerlendirildiğinde, nano dolduruculu kompozit rezinlerin mikrohibrit dolduruculu olan Gradia Direct'e göre cilalanabilirlik özellikleri daha iyi olmasına rağmen diş macun alt grubundaki nano kompozit örneklerdeki renk değişim değerleri mikrohibrit kompozit örneklere göre istatistiksel olarak daha yüksek bulunmuştur. Bu durum çalışmamızda kullanılan kompozitlerdeki monomer içeriğinin renk stabilitesini diğer faktörlerden daha çok etkilediğini göstermektedir.

Estetik beklentileri karşılamak üzere piyasaya sürülen başka bir beyazlatma ürünü olan ağız gargaralarının reçetesiz satılması, maliyetinin düşük olması ve kolay kullanılabilmeleri nedeniyle yaygın olarak tercih edilmektedir. ${ }^{25} \mathrm{Bu}$ ürünler içeriğinde bulunan hidrojen peroksitin düşük konsantrasyonlardaki etkinliği ile beyazlatma etkisi gösterirken kompozit rezinlerin yüzeylerinin pürüzlülüğünü de arttırmaktadır. ${ }^{11,26} \mathrm{Bu}$ çalışmada içeriğinde hidrojen peroksit bulunmayan ve beyazlatıcı etkili bir gargara olan Listerine Advanced White (Johnson\& Johnson, İngiltere) tercih edilmiştir. Örneklerin 12 saat gargara içerisinde bekletilmeleri, ağız içinde 1 yıl boyunca günde 2 defa gargaraya maruz kalacakları süre hesaplanarak planlanmıştır. ${ }^{27}$ ÇaIışmamızda gargara alt grubundaki örneklerde renk stabilitesi en az etkilenen Gradia Direct, en çok etkilenen ise Filtek Ultimate ve Zenit'tir. Diş macunu alt grubundaki örneklerin renk değişim değerleri, gargara alt grubundaki örneklere göre daha düşük bulunmuştur. Diş macununda bulunan aşındırıcıların çayın oluşturduğu yüzeysel renklenmeyi kaldırabilmede daha etkili olması nedeniyle beyazlatmada daha etkili olduğu düşünülebilir.

Araştırmamızda renk ölçüm işlemleri, bir spektrofotometre yardımıyla gerçekleştirilmiştir. Literatür taraması yapıldığında, dental materyallerin renklendirici solüsyonlarda bekletilmesi sonrası renk değişimlerinin değerlendirilmesinde genellikle CIELab formülasyonundan yararlanıldığı gözlenmektedir. Ancak Uluslararası Aydınlatma Komisyonu (CIE, Commission Internationale de l'Eclairage) tarafından, tüm değişkenlerin eşit değerlendirildiği CIELab $\left(\Delta E^{*}{ }_{a b}\right)$ sistemindeki eksiklikleri gidermek için gözün algısını daha baskın biçimde etkileyen faktörlerde modifikasyonlara gidilerek, kabul edilebilir ve algılanabilir renk değişimini daha uygun ve doğru biçimde saptayabilmek amacıyla CIEDE2000 formülü geliştirilmiştir. ${ }^{28}$ Çalışmalarda da bu güncel renk formülünün (CIEDE2000), dental materyallerdeki renk değişimlerinin değerlendirilmesinde algılanabilirlik ve kabul edilebilirlik noktasında CIELab formülünden daha iyi bir uyum sağladığı kanıtlanmıştır. ${ }^{29} \mathrm{Bu}$ çalışmada renk değişimlerinin tespiti için 
güncel literatüre uygun olarak CIEDE2000 formülünden yararlanıldı. Renk değişiminin değerlendirilmesinde CIEDE2000 formülasyonu için ISO/TR 28642: 2016 standardı olarak kabul edilen Paravina ve ark.' $n^{15}$ çalışmalarında tespit ettikleri, algılanabilirlik için 0.8; kabul edilebilirlik için 1.8 eşik değerleri referans alındı. Gul ve ark.' 'I ${ }^{30}$ çalışmalarında nano hibrit bir kompozit rezin, kahve ve şalgam suyunda bekletilmiş, sonrasında çeşitli beyazlatma sistemleri ile renk geri dönüşümleri değerlendirilmiştir. Renklendirme sonrasında kompozit rezinin $\Delta \mathrm{E}_{00}$ değeri 6.83 olarak ölçülürken, hidrojen peroksit içerikli ağız gargarasında bekletildikten sonra $\Delta \mathrm{E}_{00}$ değeri 4.99 olarak ölçülmüştür. Bizim çalışmamızda renklendirilen ve ardından beyazlatma uygulanan tüm örneklerden elde edilen renk değişim değerleri algılanabilirlik eşik değerinin $\left(\Delta \mathrm{E}_{00}=0.8\right)$ üzerindedir. Gradia Direct'in diş macunu alt grubundaki örnekleri haricinde çalışmamızda karşılaştıılan tüm kompozit rezinlerin renk değişim değerleri kabul edilebilirlik eşik değerinin $\left(\Delta \mathrm{E}_{00}=1.8\right)$ üzerinde olduğu tespit edilmiştir. Gargara ve diş macunu ile beyazlatma uygulamalarından sonra kompozit rezinlerde ortalama $\Delta \mathrm{E}_{00}$ sırasıyla $7.98 \pm 3.69$ ve $7.11 \pm 3.39$ olarak ölçülmüş ve ölçülen değerlerin eşik değerlerinin üzerinde olduğu tespit edilmiştir. Renklendirme prosedürünün uzun süreli olması, çay ve kahvenin yoğun renklendirme oluşturması ve reçetesiz olarak satılan gargara ve diş macununun beyazlatma etkinliğinin düşük olması kompozit rezinlerde $\Delta \mathrm{E}_{00}$ değerlerinin yüksek bulunmasının nedenleri olabilir.

$L$ değeri rengin açıklık veya koyuluğunu; pozitif $a$ kırmızıya, negatif $a$ yeşile; pozitif $b$ sarıya, negatif $b$ maviye doğru rengin meyilli olduğunu gösterir. ${ }^{31}$ Çalışmamızdaki tüm nano kompozit rezinlerin renklenme ve beyazlatma işlemleri sonrasında $L$, $a$ ve $b$ değerlerinin azaldığı; daha koyu, sarı-mavi yönde renk değişikliği sergilediği görülmüştür. Mikrohibrit kompozit rezinde ise, $L$ ve $a$ değerlerindeki değişimler minimal düzeyde kalırken, $b$ değerlerinde daha belirgin bir artış görüldüğü; sarı renk ekseni yönünde optik özellikler sergilediği görülmüştür.

Yaptığımız çalışma in vitro bir çalışma olduğundan klinik koşulları tam olarak sağlayamamaktadır. Reçetesiz satılan diğer beyazlatıcı ürünler ve bunların kompozit rezinlerin renk stabilitelerinde meydana getirebileceği değişikliklerin karşılaştıılabileceği daha uzun süreli in vivo çalışmalara intiyaç vardır.

\section{SONUÇ}

Bu çalışmanın sınırları dahilinde renklenmiş kompozit rezinlerde diş macununun, gargaraya göre daha etkili bir beyazlatma sağladığı gözlemlenmiştir. Nano kompozitler mikrohibrit kompozite göre önemli ölçüde daha fazla renk değişimi göstermiştir. Diş rengindeki kompozit rezinlerin yaygın kullanımı nedeniyle hangilerinin renk değişikliklerine daha duyarlı ve reçetesiz satılan beyazlatma ürünlerinden hangilerinin daha etkili olduğunun belirlenmesi, yapılan restorasyonun klinik ömrü açısından büyük önem taşımaktadır.

Finansal Kaynak: Bu çalışma sırasında, yapılan araştırma konusu ile ilgili doğrudan bağlantısı bulunan herhangi bir ilaç firmasından, tıbbi alet, gerec ve malzeme sağlayan ve/veya üreten bir firma veya herhangi bir ticari firmadan, çalışmanın değerlendirme sürecinde, çalışma ile ilgili verilecek kararı olumsuz etkileyebilecek maddi ve/veya manevi herhangi bir destek alınmamıştır.

Çıkar Çatışması: Bu çalışma ile ilgili olarak yazarların ve/veya aile bireylerinin çıkar çatışması potansiyeli olabilecek bilimsel ve tıbbi komite üyeliği veya üyeleri ile ilişkisi, danışmanlık, bilirkişilik, herhangi bir firmada çalışma durumu, hissedarlık ve benzer durumları yoktur.

Etik Beyan: Bu çalışma hayvanlar üzerinde yapılmamıştır ve herhangi bir insan unsuru taşımamaktadır.

\section{KAYNAKLAR}

1. Turkun LS, Turkun M. Effect of bleaching and repolishing procedures on coffee and tea stain removal from three anterior composite veneering materials. J Esthet Restor Dent. 2004;16:290-301.

2. Villalta P, Lu H, Okte Z, Garcia-Godoy F, Powers JM. Effects of staining and bleaching on color change of dental composite resins. J Prosthet Dent 2006;95:137-42.

3. Yannikakis SA, Zissis AJ, Polyzois GL, Caroni C. Color stability of provisional resin restorative materials. J Prosthet Dent. 1998;80:533-9.

4. Mundim FM, Garcia Lda F, Cruvinel DR, Lima FA, Bachmann L, Pires-de-Souza Fde C. Color stability, opacity and degree of conversion of pre-heated composites. J Dent. 2011;39 Suppl 1:e25-9.

5. Nasim I, Neelakantan $P$, Sujeer $R$, Subbarao CV. Color stability of microfilled, microhybrid and nanocomposite resins--an in vitro study. J Dent 2010; 38 Suppl 2:e137-42.

6. Ardu S, Duc O, Di Bella E, Krejci I. Color stability of recent composite resins. Odontology. 2017; 105:29-35.

7. Bagheri $R$, Burrow MF, Tyas M. Influence of foodsimulating solutions and surface finish on susceptibility to staining of aesthetic restorative materials. J Dent 2005;33:389-98.

8. Ergucu Z, Turkun LS, Aladag A. Color stability of nanocomposites polished with one-step systems. Oper Dent 2008;33:413-20.

9. Chen $\mathrm{MH}$. Update on dental nanocomposites. J Dent Res 2010;89:549-60.

10. Alharbi A, Ardu S, Bortolotto T, Krejci I. In-office 
bleaching efficacy on stain removal from CAD/CAM and direct resin composite materials. J Esthet Restor Dent 2018;30:51-8.

11. Lima FG, Rotta TA, Penso S, Meireles SS, Demarco FF. In vitro evaluation of the whitening effect of mouth rinses containing hydrogen peroxide. Braz Oral Res 2012;26:269-74.

12. Rosentritt M, Lang R, Plein T, Behr M, Handel G. Discoloration of restorative materials after bleaching application. Quintessence Int 2005; 36:33-9.

13. Hannig C, Duong S, Becker K, Brunner E, Kahler E, Attin $T$. Effect of bleaching on subsurface microhardness of composite and a polyacid modified composite. Dent Mater 2007;23:198-203.

14. Bezgin T, Ozer L, Tulga Oz F, Ozkan P. Effect of toothbrushing on color changes of esthetic restorative materials. J Esthet Restor Dent 2015;27 Suppl 1:S65-73.

15. Paravina RD, Ghinea R, Herrera $L J$, Bona $A D$, Igiel $C$, Linninger $\mathrm{M}$, et al. Color difference thresholds in dentistry. J Esthet Restor Dent 2015;27 Suppl 1:S1-9.

16. Chen X, Cuijpers V, Fan M, Frencken JE. Marginal leakage of two newer glass-ionomer-based sealant materials assessed using micro-CT. J Dent 2010; 38:731-5.

17. Ertas E, Guler AU, Yucel AC, Koprulu H, Guler E. Color stability of resin composites after immersion in different drinks. Dent Mater J. 2006;25:371-6.

18. Gonulol N, Yilmaz F. The effects of finishing and polishing techniques on surface roughness and color stability of nanocomposites. J Dent 2012;40 Suppl 2:e64-70.

19. Sideridou I, Tserki V, Papanastasiou G. Study of water sorption, solubility and modulus of elasticity of light-cured dimethacrylate-based dental resins. Biomater 2003;24:655-65.

20. Guler AU, Yilmaz F, Kulunk T, Guler E, Kurt S. Effects of different drinks on stainability of resin composite provisional restorative materials. J Prosthet Dent. 2005;94:118-24.

21. Yazici AR, Celik C, Dayangac B, Ozgunaltay G. The effect of curing units and staining solutions on the color stability of resin composites. Oper Dent. 2007;32:616-22.

22. Joiner A. Whitening toothpastes: a review of the literature. J Dent. 2010;38 Suppl 2:e17-24.

23. Guler AU, Kurt S, Kulunk T. Effects of various finishing procedures on the staining of provisional restorative materials. J Prosthet Dent 2005; 93:
453-8.

24. Atalayin C, Demirhan AO, Yasa B, Turkun LS. Is it Possible to Remove the Discolorations of Prefabricated and Direct Resin Composites by Tooth Brushing? Ege Dis Hek Fak Derg 2018;39:46-52.

25. Harorli OT, Barutcigil C. Color recovery effect of commercial mouth rinses on a discolored composite. J Esthet Restor Dent 2014;26:256-63.

26. Anagnostou M, Chelioti G, Chioti S, Kakaboura A. Effect of tooth-bleaching methods on gloss and color of resin composites. J Dent 2010;38 Suppl 2:e129-36.

27. Gurgan S, Onen A, Koprulu H. In vitro effects of alcohol-containing and alcohol-free mouthrinses on microhardness of some restorative materials. ] Oral Rehabil 1997;24:244-6.

28. Herrera LJ, Pulgar R, Santana J, Cardona JC, Guillen A, Rojas I, et al. Prediction of color change after tooth bleaching using fuzzy logic for Vita Classical shades identification. Appl Opt 2010;49: 2-9.

29. Ghinea R, Perez MM, Herrera LJ, Rivas MJ, Yebra A, Paravina RD. Color difference thresholds in dental ceramics. J Dent 2010;38 Suppl 2:e57-64.

30. Gul P, Harorlı OT, Ocal IB, Ergin Z, Barutcigil C. Color recovery effect of different bleaching systems on a discolored composite resin. Niger J Clin Pract 2017; 20: 1226-32.

31. Chang JY, Chen WC, Huang TK, Wang JC, Fu PS, Chen $\mathrm{JH}$, et al. Evaluating the accuracy of tooth color measurement by combining the Munsell color system and dental colorimeter. Kaohsiung J Med Sci 2012;28:490-4.

\section{Sorumlu Yazarın Yazışma Adresi Dr. Öğr. Üyesi Burak ÇARIKÇIOĞLU} Çanakkale Onsekiz Mart Üniversitesi, Diş Hek. Fak. Pedodonti AD. Cumhuriyet Mah. Sahilyolu Cd. No:5 Kepez, Çanakkale Tel: 02862633533/1018 e-posta: carikcioglub@gmail.com 